\title{
Effect of Preload Level on Flexural Load-carrying Capacity of RC Beams Strengthened by Externally Bonded FRP Sheets
}

\author{
Guibing Li ${ }^{1, *}$, Aihui Zhang ${ }^{2}$ and Yugang Guo ${ }^{3}$ \\ ${ }^{1}$ Department of Management Science and Engineering, Shandong Institute of Business and Technology, Yantai 264005, \\ China \\ ${ }^{2}$ College of Civil Engineering \& Architecture, Zhejiang University, Hangzhou 310058, China \\ ${ }^{3}$ College of International Business, Shandong Institute of Business and Technology, Yantai 264005, China
}

\begin{abstract}
Most of the laboratory tests investigated the flexural performance of un-preloaded or undamaged RC beams strengthened with CFRP composites. However, in engineering applications, the structural member must carry a certain load or damage. There is a lack of systematical investigations on the effects of preload or damage level on the flexural load-carrying capacity of CFRP-strengthened RC beams. This paper tested $22 \mathrm{RC}$ beams to investigate the influence of preload level on flexural load-carrying capacity of CFRP-strengthened RC beams. The test variables are preload level, amount of CFRP sheets, tension rebar ratio, and concrete strength. The test results show that if the preload level is not more than $80 \%$ of the yielding strength of the original beam, the preload or damage level does not influence the flexural load-carrying capacity of CFRP-strengthened RC beams. However, the ultimate flexural load-carrying capacity is significantly poor than that of RC beam strengthened under a preload level not more than $80 \%$ of the yielding strength, if the RC beams are strengthened under a preload level more than $90 \%$ of the yielding strength.
\end{abstract}

Keywords: CFRP-strengthened, flexural load-carrying capacity, preload level, RC beam.

\section{INTRODUCTION}

Externally bonded or near-surface mounted FRP composites have been proved to be an effective way in flexural strengthening of RC beams. Most of the laboratory tests investigated the flexural performance of un-preloaded or undamaged RC beams strengthened with bonding CFRP composites [1-3]. However, in engineering applications, the structural member must carry a certain load or damag. There is a lack of systematical investigations on the effect of preload or damage level on the flexural load-carrying capacity of CFRP-strengthened RC beams. To investigate the influence of preload or damage level on flexural performance of CFRP-strengthened RC beams, there are three scenarios adopted to simulate the service state of structure members in laboratory experimental program. In the first scenario, the RC beams were loaded up to a certain load level and unloaded and strengthened [4-7]. The second scenario adopted an approach in which RC beams were preloaded and unloaded to a predetermined level and retrofitted $[8,9]$. The third scenario used the method in which RC beams were preloaded and held the preload level

*Address correspondence to this author at the College of Management Science and Engineering, Shandong Institute of Business and Technology, Yantai, 264005, China; Tel: +86-755-6903575;

E-mails: liguibing@zju.edu.cn; leegb@sina.com and repaired with FRP composites [4, 8-17]. Due to the limitation of the quantity of tested specimen and the test variables, these investigations cannot comprehensively evaluate the effect of preload level or damage level on the flexural load-carrying capacity of CFRP-strengthened RC beams. This paper tested 25 CFRP-strengthened RC beams to investigate the influence of preload level on their flexural load-carrying capacity.

\section{AIMS AND SCOPE}

It is generally believed that removing the load applied to the structure, to strengthen it with bonding FRP composites, is favorable towards improving its flexural performance of the strengthened structure members. Taking the Code CECS146 [18] as an example, the provision 4.1.6 suggested that it is better to remove the live load applied on the structure at bonding CFRP sheets to strengthen the structural member. There are still lack of systematic experiment studies on how the applied load or the damage level affects the flexural performance of strengthened structural member or whether the applied load should be removed at strengthening. To achieve better understanding of the effect of applied load or damage level on the flexural performance of the strengthened structural member, 22 reinforced concrete beams were preloaded at different levels which 
sustained the load level constant and strengthened epoxybonded CFRP sheets to investigate their flexural performance.

\section{SUMMARY OF RELATED LITERATURES}

Arduini and Nanni [4] carried out experimental studies on 8 RC beams which were firstly preloaded up to $30 \%$ of the yielding strength of the control beams, then unloaded and bonded with CFRP sheets. Two specimens were subjected to the sustaining load level (simulating the total service load) during the adhesion of the CFRP sheets. It was shown that, for damaged specimens, the specimen strengthened without sustaining load had an average flexural load-carrying capacity increase of $24 \%$ over the control beam, while the specimen strengthened under sustaining load had an increase of only $16 \%$ over the control beam. Because the failure was controlled by FRP debonding, there was no substantial difference in ultimate load-carrying capacity of the specimens.

Norris et al., [5] tested nineteen beams which were loaded beyond concrete cracking strength, and retrofitted with three different CFRP systems. The beams were subsequently loaded to failure. Different modes of failure and gain in the ultimate strength were observed, depending on the orientation of the fiber. The objective of this study was to investigate the effect of CFRP sheets on strength and stiffness of the beams strengthened under different orientations of the fibers with respect to the axis of the beam. No assessment had been done on the effect of damage level on flexural load-carrying capacity.

Richardson and Fam [6] took two different pre-repair loading histories simulated in $3,000 \times 300 \times 150 \mathrm{~mm} \mathrm{RC}$ beams, namely cracking within the elastic range, and overloading in the plastic range to investigate the influence of damage level on the flexural performance of CFRPstrengthened RC beams. After unloading, the beams were strengthened with either high or ultrahigh modulus (210 or $400 \mathrm{GPa}$ ) CFRP plates, or a hybrid system. The test results show that the level of preexisting damage has an insignificant effect on strengthening effectiveness and failure mode at ultimate.

Fayyadh and Razak [7] investigated the effect of damage level on the effectiveness of CFRP sheets as repair system and its influence on the stiffness recovery. Three pre-cracked $\mathrm{RC}$ beams were tested. The beams were initially damaged under design load limit, steel yield load limit and ultimate load limit. The experimental result shows that the CFRP strengthening technique increases the load-carrying capacity regardless of the damage level, where it increases the load capacity by $83 \%, 56 \%$ and $48 \%$ for the damage levels of $35 \%, 66 \%$ and $100 \%$ respectively.

Cao et al., [8] investigated the flexural behavior of preloaded RC beams strengthened with CFRP sheets. The beams were preloaded up to $50 \%$ of ultimate load of the control beam or preloaded up to $50 \%$ then unloaded to $25 \%$ and held the load constant and strengthened with CFRP sheets before resuming the loading up to failure. Test results show that the ultimate load-carrying capacity improved significantly regardless of the preload level; the higher preload level, the less improvement in ultimate load.

Wang and Chang [9] tested eight preloaded RC beams strengthened with CFRP sheets. The beams were preloaded up to $40 \%, 60 \%$, and $80 \%$ of the yielding load of the control beam and sustained and strengthened with near-surface mounted CFRP composites. Experimental result shows that the ultimate load-carrying capacity of preloaded RC beams is almost the same as that of the strengthened beam without preloading.

Shin and Lee [10] tested six CFRP-strengthened beams subjected to different sustaining loads. The sustaining load levels at the time of bonding CFRP laminates corresponded to $0 \%, 50 \%$ and $70 \%$ of nominal flexural strength of the control RC beam, respectively. Experimental results showed that sustaining load levels had more influence on deflections of beams at the yielding and ultimate stage than the ultimate strength of the beam; the sustaining load level did not influence the yielding strength and ultimate strength of the strengthened RC beams. Due to the fact that the strengthened beams failed by debonding of CFRP laminates, the authors concluded that it was difficult to judge the effect of the sustaining load levels on the ultimate strength of the strengthened beams.

Wang and Li [11-13] tested six RC beams strengthened in flexure using CFRP sheets subjected to different sustaining load level and loading history. The experimental results show that the initial load is an important factor affecting the ultimate strength of CFRP-strengthened RC beams. Beams strengthened at higher sustaining load level have a lower ultimate strength than those beams strengthened at lower sustaining load levels. If the initial applied load is the same, the ultimate strength of CFRPstrengthened RC beams is almost same regardless of the sustaining load level and load history at the time of strengthening.

Wu et al., [14] tested ten RC beams strengthened by bonding hybrid carbon systems to study whether the capacity of the loaded beam in service can be restored to their capacities after the structural upgrading. The simply supported beam was first loaded up to 40 or $60 \%$ of steel yielding load of the reference beam without strengthening, with the prescribed load held constant, CFRP sheets were bonded to the tensile face of the beam. This preloading procedure was to simulate a structure in service and to introduce the possible damage caused by the service load. Due to the fact that the other test variables were different, the authors did not analyze the influence of preloading level on flexural load-carrying capacity of the strengthened RC beams.

Shahawy et al., [15] tested seven T-girders to evaluate the performance of pre-cracked girders retrofitted with CFRP fabric under service load. The girders were preloaded up to 65 , 85 , and $117 \%$ of control yield moment and locked and strengthened with two layers of CFRP wraps before resuming the loading up to failure. The results demonstrate that the preload level prior to the installation of CFRP does not affect the overall behavior of the wrapped specimens. Preloaded partially wrapped members, however, exhibit less 
ductility and strength than the corresponding preloaded fully wrapped specimens.

Benjeddou et al., [16] studied the effectiveness of the CFRP laminates on the load capacity and the rigidity of the damaged reinforced concrete beams strengthened with CFRP laminates. CFRP sheets were bonded in the tensile face of the damaged beams. The most investigated parameter in this work is the damage level of RC beams, which were taken as $0 \%, 80 \%, 90 \%$ and $100 \%$ of the load capacity of the control beam. Experimental results show that repairing damaged RC beams with externally bonded CFRP sheets was successful for different damage degrees. The strengthening effectiveness of damaged RC beams with damage level lower than $80 \%$ of its original load capacity is much more significant than the beams with damage level over $90 \%$ of its original load capacity.

Xiong and $\mathrm{Xu}$ [17] investigated the flexural behavior of preloaded RC beams strengthened by bonding hybrid CFRP sheets and steel plates. Three beams were preloaded up to $0 \%, 50 \%$, and $70 \%$ of the flexural strength of the control beam and sustained and retrofitted. Experimental results show that the preloaded level has no effect on the flexural load-carrying capacity of strengthened beams.

\section{EXPERIMENTAL PROGRAMS}

Two batches of beams were tested in the present study. The first batch includes sixteen CFRP-strengthened RC beams and two control beams without strengthening. The test variables include the preload level at bonding CFRP sheets, the amount of CFRP sheets, concrete strength, and the amount of tension rebar, respectively. According to the variables of tension rebar and CFRP sheets, 16 CFRPstrengthened RC beams were divided into four series A1, $\mathrm{A} 2$, B1, and B2, respectively.

All specimens have the same dimension, $2500 \mathrm{~mm}$ long, with the cross section of $150 \mathrm{~mm}$ wide and $250 \mathrm{~mm}$ high. Two rebars of $12 \mathrm{~mm}$-diameter for series $\mathrm{A}$ and two ones of $16 \mathrm{~mm}$-diameter for series B were used as the longitudinal reinforcement. The closed-type stirrups of $8 \mathrm{~mm}$-diameter bars were spaced at $100 \mathrm{~mm}$ for series $\mathrm{A}$ and $70 \mathrm{~mm}$ for series $\mathrm{B}$ along the beam length. The length of CFRP laminate is $1800 \mathrm{~mm}$ long with the width of $150 \mathrm{~mm}$ to avoid a premature end debonding. All beams with CFRP strengthened were designed to be flexural failure in order to study the flexural behavior of the strengthened beams.

The details of specimens are summarized in Table $\mathbf{1}$. Fig. (1) illustrates the dimensions and reinforcement arrangement of the specimens. For the convenience of bonding FRP sheets and ensuring bonding quality, reverse loading was used in the experimental tests, as shown in Fig. (2). Material properties are listed in Table 2.

The second batch includes 9 CFRP-strengthened RC beams and one control beam. Test variables are the number of plies of CFRP sheet, preload level at the time of strengthening, and anchor program of CFRP laminate at beam-column joint. The specimens were divided into three

Table 1. Specimen and experimental parameters.

\begin{tabular}{|c|c|c|c|c|}
\hline \multicolumn{2}{|c|}{ Specimens } & \multirow{2}{*}{ Rebar } & \multirow{2}{*}{$\begin{array}{l}\text { CFRP } \\
\text { (plies) }\end{array}$} & \multirow{2}{*}{ Preload $^{*}$} \\
\hline A & B & & & \\
\hline AC & $\mathrm{BC}$ & \multirow{9}{*}{$\begin{array}{c}2 \phi 12 \\
(2 \phi 16)\end{array}$} & \multicolumn{2}{|c|}{ Control Beams } \\
\hline $\mathrm{A} 10^{*}$ & B10 & & 1 & - \\
\hline A20 & B20 & & 2 & - \\
\hline A13 & B13 & & 1 & $0.3 P_{y}$ \\
\hline A16 & B16 & & 1 & $0.6 P_{y}$ \\
\hline A18 & B18 & & 1 & $0.8 P_{y}$ \\
\hline A23 & B23 & & 2 & $0.3 P_{y}$ \\
\hline A26 & B26 & & 2 & $0.6 P_{y}$ \\
\hline A28 & B28 & & 2 & $0.8 P_{y}$ \\
\hline
\end{tabular}

*Specimens are labeled as RFP, such as A10, where R, $\mathrm{F}$, and $\mathrm{P}$ stand for number of tension rebar ( $\mathrm{R}=\mathrm{A}, \mathrm{B})$, plies of CFRP sheets (F=1, 2), and the sustaining load level ( $\mathrm{P}=0,3,6$, and 8 , correspond to $0,30 \%, 60 \%$ and $80 \%$ of the flexural yielding load of the control beam, respectively). $P_{y^{-}}$flexural yielding load of control beam.
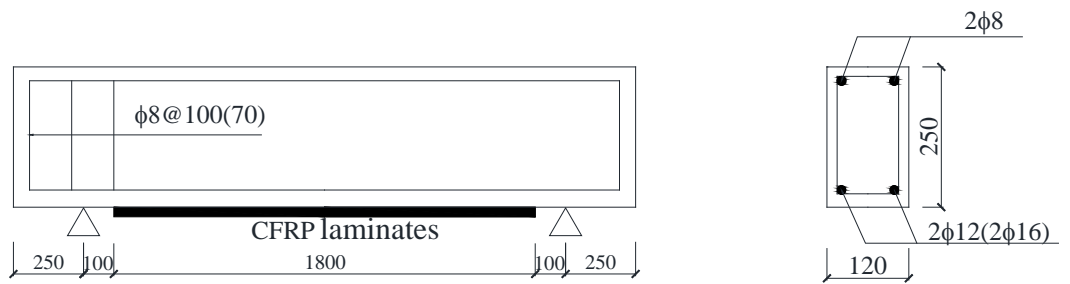

Fig. (1). Dimensions and reinforcement arrangement of specimen. 


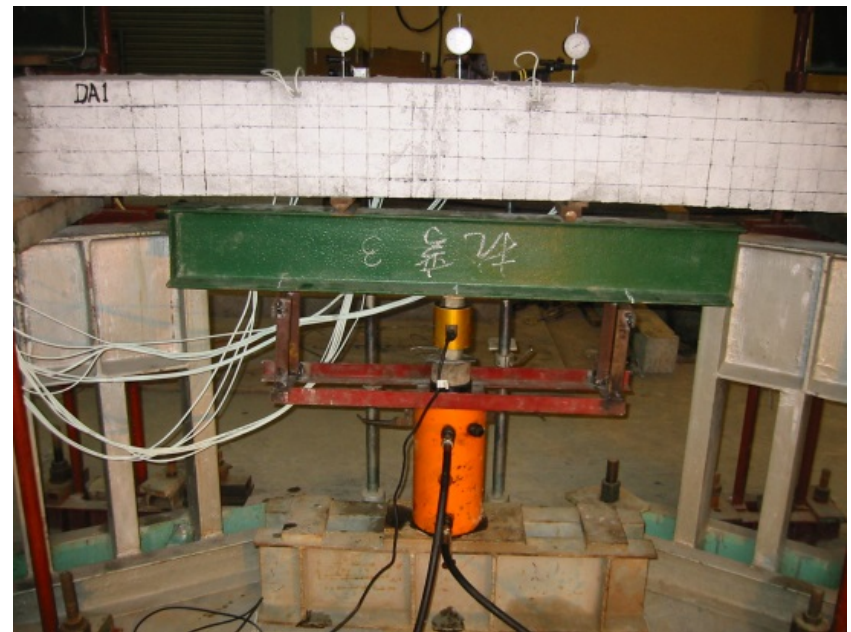

Fig. (2). Test-setup of A2 and B2 series.

series, B1e, B2e, and B2i, by the amount of CFRP sheets and anchorage method. Fig. (3) shows the dimensions and reinforcement arrangement of the specimens. The details of the specimens are summarized in Table 3.

There are three beams in each series, the beams were loaded up to $0,30 \%$, and $60 \%$ of the yielding strength of unstrengthened control beam, respectively. Then, sustaining the applied load constantly, CFRP sheets were bonded on the tension face of RC beam sequentially. After the epoxy solidified, the strengthened beams were reloaded to failure.
The main purpose of the test was to investigate the flexural performance of beam section at negative moment region strengthened by bonding CFRP sheets.

\section{RESULTS AND DISCUSSION}

\section{Failure Modes}

There are two failure modes in series A1, A2, B1, B2, $\mathrm{B} 1 \mathrm{e}, \mathrm{B} 2 \mathrm{e}$, and $\mathrm{B} 2 \mathrm{i}$, one is CFRP tensile rupture, Fig. (4a, b); the other is intermediate crack induced debonding, Fig. (5ad). 19 of the 22 CFRP-strengthened beams in all series failed by the intermediate crack induced (IC) debonding, their debonding process and characteristics are all the same.

Taking beam B23 as an example, the first flexural crack occurred when the applied load reached $12.9 \mathrm{kN}$. When the applied load reached the designed preload $19.5 \mathrm{kN}$, sustaining this applied load constantly, FRP sheets were bonded on the tension face of RC beam sequentially. After the epoxy solidified, the strengthened beam was reloaded to failure. As the applied load reached $84.5 \mathrm{kN}$, the tension rebar yielded. At this time, there are six flexural cracks developed at the constant moment region and eight flexureshear cracks initiated at the shear spans, and one of the flexure-shear cracks near the loading point became the critical flexure-shear crack (CFSC), as shown in Fig. (5a). When the applied load reached $90.5 \mathrm{kN}$, tributary cracks (TC) initiated in front of the CFSC, as shown in Fig. (5b). At the post-yield stage, the amount of cracks remains unchanged, the width of the main flexural crack augmented

Table 2. Material properties (MPa)

\begin{tabular}{|c|c|c|c|c|}
\hline \multirow{2}{*}{ Series } & Concrete & Rebar & Stirrup & $\boldsymbol{f}_{\mathbf{y v}}$ \\
\cline { 2 - 5 } & $\boldsymbol{f}_{\mathrm{c}}^{*}$ & $\boldsymbol{f}_{\mathrm{y}}$ & 276 & 3350 \\
\hline A1, A2 & 13.4 & 381 & 276 & 3350 \\
\hline B1, B2 & 16.7 & 381 & 276 \\
\hline B1e, B2e, B2i & 35.5 & 381 & 4150 \\
\hline
\end{tabular}

$* f_{c}$, the compression strength of concrete; $f_{\mathrm{y}}$, yielding strength of steel rebar; $f_{\mathrm{yv}}$ yielding strength of stirrup; $f_{\mathrm{u}}$ ultimate tensile strength of CFRP sheet, respectively.

Table 3. Specimens and test variables

\begin{tabular}{|c|c|c|c|c|c|}
\hline \multirow[t]{2}{*}{ Series } & Beam & Rebar & $\begin{array}{l}\text { CFRP } \\
\text { (Plies) }\end{array}$ & Preload & $\begin{array}{l}\text { Anchor } \\
\text { Program }\end{array}$ \\
\hline & $\mathrm{BC}$ & \multirow{10}{*}{$4 \phi 16$} & 0 & - & - \\
\hline \multirow{3}{*}{ B1e } & $\mathrm{B} 10 \mathrm{e}^{*}$ & & 1 & 0 & external \\
\hline & B13e & & 1 & $0.3 P_{\mathrm{y}}$ & external \\
\hline & B16e & & 1 & $0.6 P_{\mathrm{y}}$ & external \\
\hline \multirow{3}{*}{ B2e } & B20e & & 2 & 0 & external \\
\hline & B23e & & 2 & $0.3 P_{\mathrm{y}}$ & external \\
\hline & B26e & & 2 & $0.6 P_{\mathrm{y}}$ & external \\
\hline \multirow{3}{*}{ B2i } & B20i & & 2 & 0 & internal \\
\hline & B23i & & 2 & $0.3 P_{\mathrm{y}}$ & internal \\
\hline & B26i & & 2 & $0.6 P_{\mathrm{y}}$ & internal \\
\hline
\end{tabular}

${ }^{*}$ Specimens are labeled as BFPA, such as B10e, where B, F, P, and A stand for beam (B), plies of CFRP sheets (F=1, 2), and the preload level (P=0, 3, 6, and 8, correspond to 0, 30\%, $60 \%$ and $80 \%$ of the flexural yielding load of the control beam, respectively), and anchorage of CFRP sheets (e and i denote external anchorage and internal anchorage), respectively. 


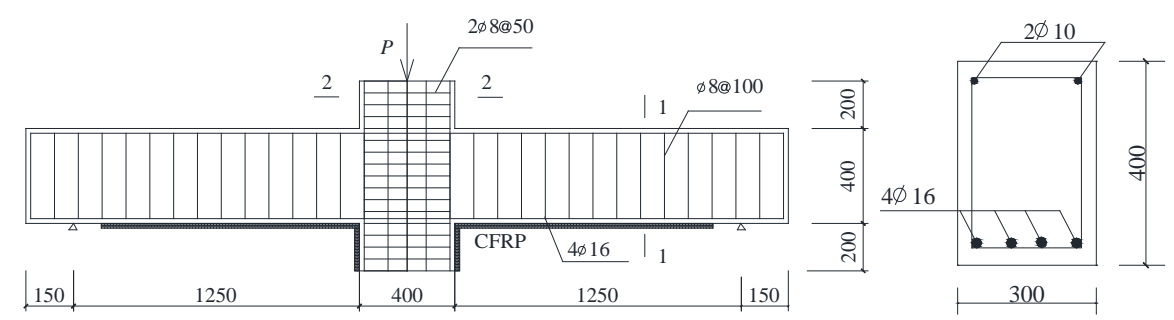

Fig. (3). Dimensions and reinforcement arrangement of B1e, B2e, and B2i.

slightly. However, the width of the CFSC and TC was more pronounced with the increase in deflection. When the applied load reached $96.6 \mathrm{kN}$, debonding initiated at the tip of the TC, as shown in Fig. (5c). Moreover, it can be clearly observed that the moment curvature of the shear span and the constant moment region were not in continuity, as shown in Fig. (5d). The reason is that the plastic hinge was formed in the vicinity of the CFSC after tension rebar yielding. Moreover, the crack space, crack width, and crack depth of flexure-shear cracks are all less than that of flexural cracks in the constant moment region. As a result, the flexural stiffness of beam section at the shear span must be higher than that at the constant moment region. Therefore, the shear span of the beam rotated around the CFSC section leading to the discontinuity of moment curvature of RC beam left and right of the CFSC section, and was associated with the formation of relative vertical displacement between the two halves of the CFSC section.

\section{Discussion of the Effect of Preload Level on Flexural Load-Carrying Capacity}

Beams A16, A18, B13, B16, and B18 were failed by CFRP rupture, while Beams A10, A13, and B10 were IC debonding failure. However, the ultimate tensile strain in CFRP laminates at initial debonding of beams A10, A13, and B10 is very close to that at rupture. Therefore, the test results of series $\mathrm{A} 1$ and $\mathrm{B} 1$ are bracketed together to evaluate

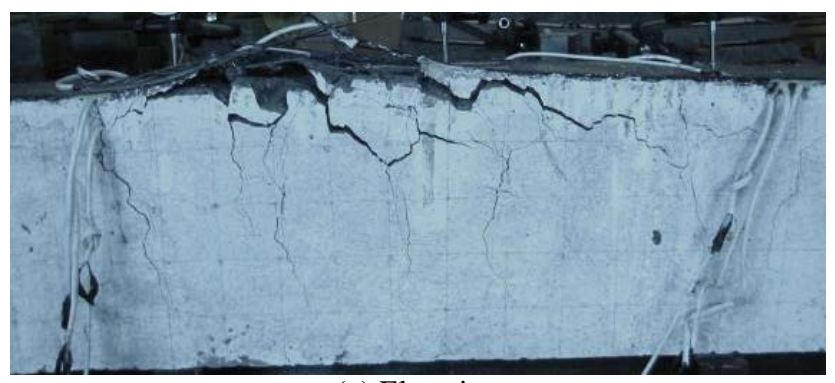

(a) Elevation

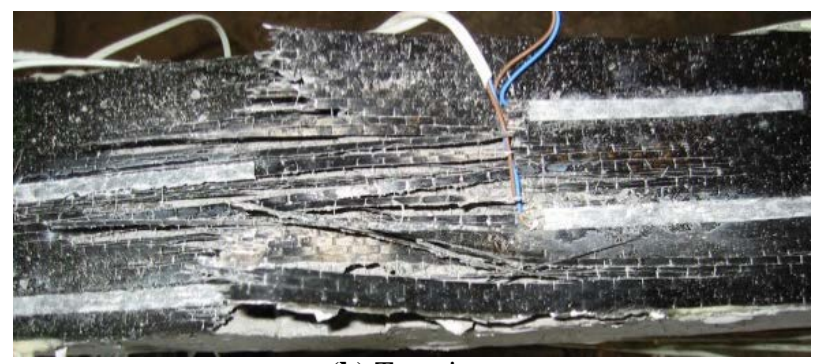

(b) Top view

Fig. (4). CFRP rupture of B18. the effect of preload level on ultimate flexural load-carrying capacity. The ultimate state of these beams is CFRP laminates rupture; consequently, the applied load on the beam at this moment is the ultimate load-carrying capacity of the strengthened beam.

Table 4 shows the tested ultimate load-carrying capacity of each strengthened beams and the statistical analysis results of the effect of preload level on flexural load-carrying capacity of each series. The ultimate loads of beams A10, A13, A16, and A18 are 59.5, 56.5, 63.4, and $63.8 \mathrm{kN}$,

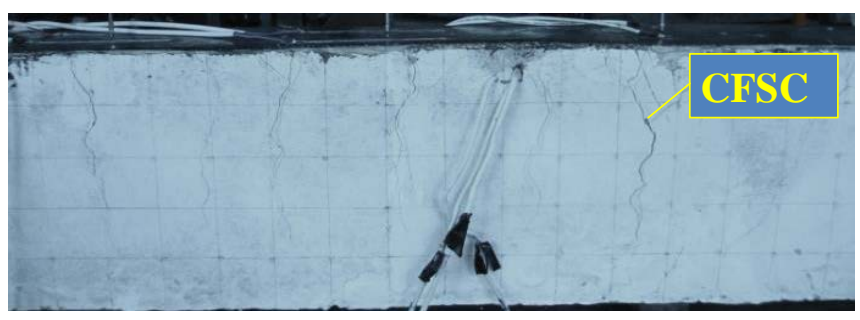

(a) Critical flexure-shear crack (CFSC).

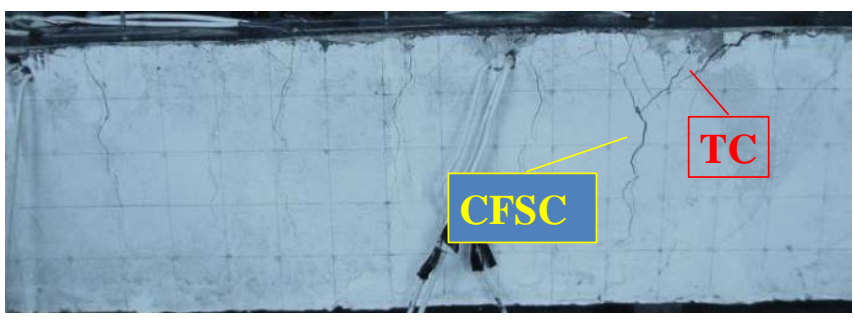

(b) Tributary crack (TC) initiated near the tip of CFSC.

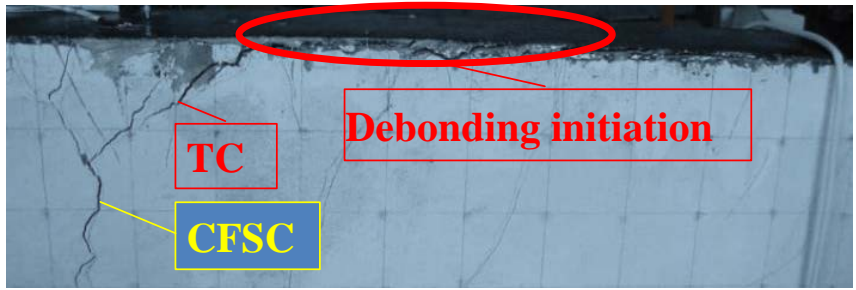

(c) Debonding initiated at the tip of TC.

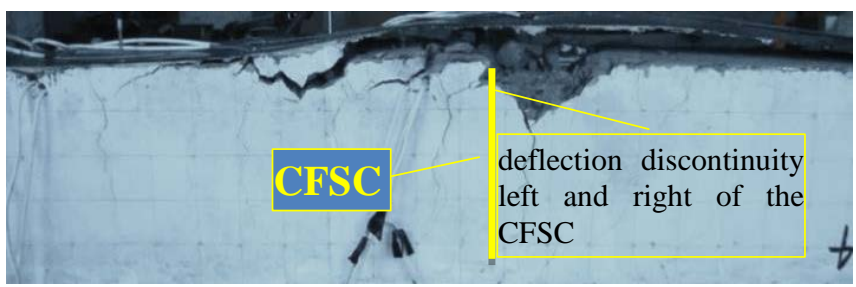

(d) Deflection discontinuity left and right of the CFSC.

Fig. (5). Debonding process and characteristics of beam B23. 
respectively; their average is $60.8 \mathrm{kN}$ with coefficient of variation $4.9 \%$. The ultimate loads of beams B10, B13, B16, and B18 are 90.8, 91.3, 92.1, and $90.1 \mathrm{kN}$, respectively; their average is $91.1 \mathrm{kN}$ with coefficient of variation $0.8 \%$. Fig. (6) shows the relationship between the ultimate loads and preload levels of the two series.

All the strengthened beams in series A2, B2, B1e, B2e, and $\mathrm{B} 2 \mathrm{i}$ were failed by IC debonding. Therefore, the test results of these four series are bracketed together to assess the influence of preload level on ultimate flexural loadcarrying capacity. The ultimate state of these beams is the initial debonding of CFRP laminates; the applied load on the beam at this moment is the ultimate load-carrying capacity of the strengthened beam.

As shown Table 4, the ultimate loads of beams A20,
A23, A26, and A28 are 66.4, 69.5, 68.1, and $64.0 \mathrm{kN}$, respectively; their average is $67.0 \mathrm{kN}$ with coefficient of variation 3.1\%. The ultimate loads of beams B20, B23, B26, and $\mathrm{B} 28$ are 83.6, 96.6, 96.1, and $89.6 \mathrm{kN}$, respectively; their average is $91.5 \mathrm{kN}$ with coefficient of variation $5.8 \%$. The ultimate loads of beams B10e, B13e, and B16e are 218.2, 233.0, and $233.6 \mathrm{kN}$, respectively; their average is $204.9 \mathrm{kN}$ with coefficient of variation $4.7 \%$. The ultimate loads of beams B20e, B23e, and B26e are 218.2, 233.0, and 233.6 $\mathrm{kN}$, respectively; their average is $228.3 \mathrm{kN}$ with coefficient of variation 3.1\%. The ultimate loads of beams B20i, B23i, and B26i are 227.0, 223.0, and $222.0 \mathrm{kN}$, respectively; their average is $223.8 \mathrm{kN}$ with coefficient of variation $1.3 \%$.

The coefficients of variation of ultimate loads of the seven series are in the range of $0.8 \% \sim 5.8 \%$, this indicates that the preload level does not influence the ultimate load-

Table 4. Test results and statistical analysis of ultimate applied loads of strengthened RC beams.

\begin{tabular}{|c|c|c|c|c|c|}
\hline Series & Beam & $P_{\mathrm{u}}^{*}, \mathrm{kN}$ & Average, kN & Cov., \% & Failure mode \\
\hline \multirow{4}{*}{$\mathrm{A} 1$} & A10 & 59.5 & \multirow{4}{*}{60.8} & \multirow{4}{*}{4.9} & IC debonding \\
\hline & A13 & 56.5 & & & IC debonding \\
\hline & A16 & 63.4 & & & CFRP rupture \\
\hline & A18 & 63.8 & & & CFRP rupture \\
\hline \multirow{4}{*}{ B1 } & B10 & 90.8 & \multirow{4}{*}{91.1} & \multirow{4}{*}{0.8} & IC debonding \\
\hline & B13 & 91.3 & & & CFRP rupture \\
\hline & B16 & 92.1 & & & CFRP rupture \\
\hline & B18 & 90.1 & & & CFRP rupture \\
\hline \multirow{4}{*}{ A2 } & A20 & 66.4 & \multirow{4}{*}{67.0} & \multirow{4}{*}{3.1} & IC debonding \\
\hline & A23 & 69.5 & & & IC debonding \\
\hline & A26 & 68.1 & & & IC debonding \\
\hline & A28 & 64.0 & & & IC debonding \\
\hline \multirow{4}{*}{ B2 } & B20 & 83.6 & \multirow{4}{*}{91.5} & \multirow{4}{*}{5.8} & IC debonding \\
\hline & B23 & 96.6 & & & IC debonding \\
\hline & B26 & 96.1 & & & IC debonding \\
\hline & B28 & 89.6 & & & IC debonding \\
\hline \multirow{3}{*}{ B1e } & B10e & 218.4 & \multirow{3}{*}{204.9} & \multirow{3}{*}{4.7} & IC debonding \\
\hline & B13e & 200.4 & & & IC debonding \\
\hline & B16e & 196.0 & & & IC debonding \\
\hline \multirow{3}{*}{ B2e } & B20e & 218.2 & \multirow{3}{*}{228.3} & \multirow{3}{*}{3.1} & IC debonding \\
\hline & B23e & 233.0 & & & IC debonding \\
\hline & B26e & 233.6 & & & IC debonding \\
\hline \multirow{3}{*}{ B2i } & B20i & 227.0 & \multirow{3}{*}{223.3} & \multirow{3}{*}{1.3} & IC debonding \\
\hline & B23i & 223.0 & & & IC debonding \\
\hline & B26i & 220.0 & & & IC debonding \\
\hline
\end{tabular}


Table 5. Crack width of the critical shear-flexure crack of the strengthened RC beams

\begin{tabular}{|c|c|c|c|c|c|}
\hline Series & Beam & $* \omega_{\text {preload }}(\mathrm{mm})$ & $\omega_{\text {debond }}(\mathbf{m m})$ & $\omega_{\text {debond }}-\omega_{\text {preload }}$ & Failure mode \\
\hline \multirow{4}{*}{$\mathrm{A} 1$} & A10 & 0 & 1.60 & 1.60 & IC debonding \\
\hline & A13 & 0.20 & 1.70 & 1.50 & IC debonding \\
\hline & A16 & 0.30 & - & - & CFRP rupture \\
\hline & A18 & 0.50 & - & - & CFRP rupture \\
\hline \multirow{4}{*}{ B1 } & B10 & 0 & 0.50 & 0.50 & IC debonding \\
\hline & B13 & 0.10 & - & - & CFRP rupture \\
\hline & B16 & 0.20 & - & - & CFRP rupture \\
\hline & B18 & 0.30 & - & - & CFRP rupture \\
\hline \multirow{4}{*}{ A2 } & A20 & 0 & 1.40 & 1.40 & IC debonding \\
\hline & A23 & 0.20 & 1.55 & 1.35 & IC debonding \\
\hline & A26 & 0.25 & 1.45 & 1.20 & IC debonding \\
\hline & A28 & 0.30 & 1.50 & 1.20 & IC debonding \\
\hline \multirow{4}{*}{ B2 } & B20 & 0 & 1.40 & 1.40 & IC debonding \\
\hline & B23 & 0.10 & 1.50 & 1.40 & IC debonding \\
\hline & B26 & 0.25 & 1.60 & 1.35 & IC debonding \\
\hline & B28 & 0.30 & 1.70 & 1.40 & IC debonding \\
\hline \multirow{3}{*}{ B1e } & B10e & 0 & 0.50 & 0.50 & IC debonding \\
\hline & B13e & 0.15 & 0.70 & 0.55 & IC debonding \\
\hline & B16e & 0.25 & 0.80 & 0.55 & IC debonding \\
\hline \multirow{3}{*}{ B2e } & B20e & 0 & 0.40 & 0.40 & IC debonding \\
\hline & B23e & 0.10 & 0.60 & 0.50 & IC debonding \\
\hline & B26e & 0.20 & 0.60 & 0.40 & IC debonding \\
\hline \multirow{3}{*}{ B2i } & B20i & 0 & 0.45 & 0.45 & IC debonding \\
\hline & B23i & 0.10 & 0.50 & 0.40 & IC debonding \\
\hline & B26i & 0.15 & 0.55 & 0.40 & IC debonding \\
\hline
\end{tabular}

$* \omega_{\text {preload }}$ and $\omega_{\text {debond }}$ denote the crack width of the critical shear-flexure crack of the strengthened RC beams under the applied preload level and at initiation of CFRP laminates debonding, respectively.

carrying capacity of flexurally CFRP-strengthened RC beams. Fig. (7) shows the relationship between the ultimate loads and preload levels of the four series.

The main failure mode of the strengthened $\mathrm{RC}$ beams is the critical flexure-shear crack induced debonding failure. The greater the opening of the critical flexure-shear crack is, the more tensile deformation will be generated in the CFRP composites in the vicinity of this crack. Consequently, tensile stress concentration in the CFRP composites will be generated which induces the augment of shear stress in the FRP-concrete interface. This will promote the premature debonding failure. Therefore, the critical flexure-shear crack width is the main factor affecting CFRP laminate debonding. It was found in the experimental test that the width of the critical flexure-shear crack in the strengthened RC beams was within the range of $0 \sim 0.30 \mathrm{~mm}$ when the beams were applied to its preload level. Table 5 shows the crack width of the critical shear-flexure crack of the strengthened RC beams under the applied preload level and at initiation of CFRP laminates debonding. It can be seen that the relative increments of the critical flexure-shear crack width after bonding CFRP sheets are almost the same at the time of initiation of CFRP laminates debonding. This indicates that FRP debonding is dominated by the relative increment of the flexure-shear crack width, rather than by the absolute width of the critical crack. Therefore, if the applied load level does not make the RC beam reach its yield strength, the preload level or the damage level has almost no effect on the flexural debonding load carry capacity of the strengthened RC beams. 


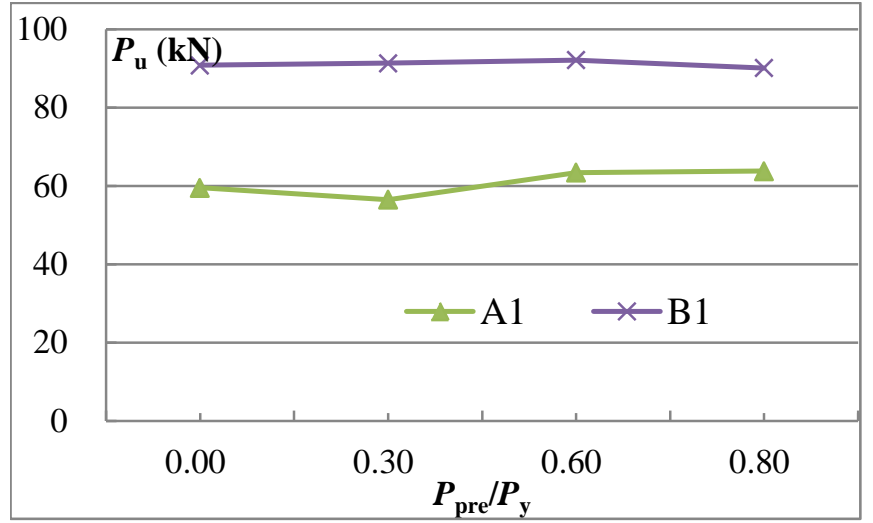

Fig. (6). Effect of preload level on ultimate load-carrying capacity.

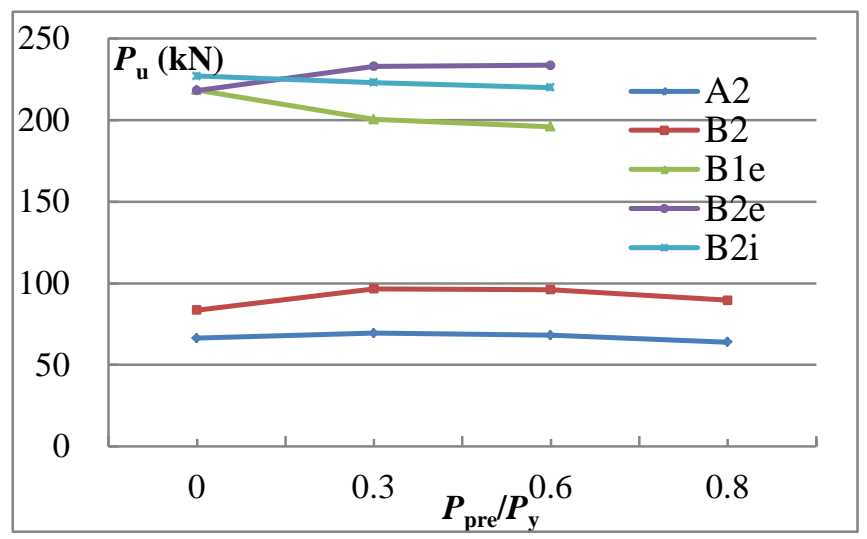

Fig. (7). Effect of preload level on ultimate load-carrying capacity.

\section{CONCLUSION}

This paper investigates and analyzes the effect of preload level on flexural load-carrying capacity of FRP-strengthened $\mathrm{RC}$ beams based on the test results. Within the scope of the present and related experimental results, the following conclusions can be drawn from this study:

- Bonding CFRP composites on the tension face of preloaded or damaged RC beams can significantly improve its flexural performance. If the preload level is not more than $80 \%$ of the yielding strength of the original RC beam, the ultimate flexural load-carrying capacities of the strengthened beams are almost the same regardless of the preload or damage level.

- The preload or damage level does not influence the flexural load-carrying capacity of flexurally CFRPstrengthened RC beams. Therefore, the effect of preload level or damage level on flexural load-carrying capacity can be ignored in flexural design of CFRP-strengthened RC beams.

- Very limited test results show that the ultimate flexural load-carrying capacity of RC beam strengthened under preload level, with more than $90 \%$ of the yielding strength of the original beam being significantly poor than that of RC beam strengthened under a preload level not more than $80 \%$ of the yielding strength. This issue, which remains under-investigation, must be given the attention it deserves through further experimental and analytical studies.

\section{CONFLICT OF INTEREST}

The authors confirm that this article content has no conflict of interest.

\section{ACKNOWLEDGEMENTS}

Declared none.

\section{REFERENCES}

[1] C. B. Demakos, C. C. Repapis, and D. Drivas, "Investigation of structural response of reinforced concrete beams strengthened with anchored FRPs," Open Const. Build. Technol. J., vol. 7, pp. 146157, 2013.

[2] C. C. Spyrakos, C. A. Maniatakis, E. Smyrou, and I. N. Psycharis, "FRP strengthened brick-infilled RC frames: an approach for their proper consideration in design," Open Const. Build. Technol. J., vol. 6, pp. 306-324, 2012.

[3] G. J. Mitolidis, T. N. Salonikios, and A. J. Kappos, "Mechanical and bond characteristics of SRP and CFRP reinforcement-a comparative research," Open Const. Build. Technol. J., vol. 2, pp. 207-216, 2008.

[4] M. Arduini and A. Nanni, "Behavior of precracked RC beams strengthened with carbon FRP sheets," J. Compos. Constr., vol. 1, pp. 63-70, 1997.

[5] T. Norris, H. Saadatmanesh, and M. R. Ehsani, "Shear and flexural strengthening of R/C beams with carbon fiber sheets," ASCE. J. Struct. Eng., vol. 123, pp. 903-11, 1997.

[6] T. Richardson and A. Fam, "Modulus effect of bonded cfrp laminates used for repairing preyield and postyield cracked concrete beams," J. Compos. Constr., vol. 18, no. 4, p. 04013054 , 2014.

[7] M. M. Fayyadh, and H. Abdul Razak, "Assessment of effectiveness of CFRP repaired RC beams under different damage levels based on flexural stiffness," Constr. Build. Mater., vol. 37, pp. 125-134, 2012.

[8] G. Cao, Z. Fang, and J. Wu, "Experimental study on RC beams strengthened with FRP laminates "Build. Struct., vol. 35, p. 4, 2005.

[9] T. Wang and Y. Chang, "Experimental research on the flexural behavior of RC beams strengthened by NSM CFRP sheets," $J$. Wuhan Univ. Technol., vol. 31, p. 5, 2009.

[10] Y.S. Shin and C. Lee, "Flexural behavior of rc beams strengthened with carbon fiber-reinforced polymer laminates at different levels of sustaining load," ACI Struct. J., vol. 100, pp. 231-39, 2003.

[11] W. Wenwei and L. Guo, "Experimental study and analysis of RC beams strengthened with CFRP laminates under sustaining load," Int. J. Solids Struct., vol. 43, pp. 1372-1387, 2006.

[12] W. Wang, G. Zhao, C. Huang, and H. Ren, "An experimental study of strengthening of initially loaded reinforced concrete beams using CFRP sheets," Eng. Mech., vol. 21, p. 7, 2004.

[13] W. Wang, G. Zhao, and C. Huang, "An experimental study of RC beams strengthened with CFRP sheets under simulated continuous traffic loads," Eng. Mech., vol. 23, p. 6, 2006.

[14] Z. Wu, Y. Shao, K. Iwashita, and K. Sakamoto, "Strengthening of preloaded RC beams using hybrid carbon sheet," J. Compos. Const., vol. 11, pp. 299-307, 2007.

[15] M. Shahawy, O. Chaallal, T. E. Beitelman, and A. El-Saad, "Flexural strengthening with carbon fiber-reinforced polymer composites of preloaded full-scale girders," Struct. J., vol. 98, pp. 735-742, 2001.

[16] O. Benjeddou, M. B. Ouezdou, and A. Bedday, "Damaged RC beams repaired by bonding of CFRP laminates," Constr. Build. Mater., vol. 21, pp. 1301-1310, 2007.

[17] X. Xiong and $\mathrm{H}$. Xu, "Experimental research and parametric analysis on flexural performance of reinforced concrete beams combination strengthened with bonded CFRP and steel plates under sustaining load," Build. Struct., vol. 40, p. 6, 2010. 
[18] CECS-146, "Techinical Specification for Strengthening Concrete Structures with Carbon Fiber Reinforced Polymer Laminate,"
China Association for Engineering Constraction Standardization, Beijing: China Planning Press, 2003, p. 53.

Received: May 22, 2014

(c) Li et al.; Licensee Bentham Open.

This is an open access article licensed under the terms of the Creative Commons Attribution Non-Commercial License (http://creativecommons.org/licenses/by-nc/3.0/) which permits unrestricted, non-commercial use, distribution and reproduction in any medium, provided the work is properly cited. 